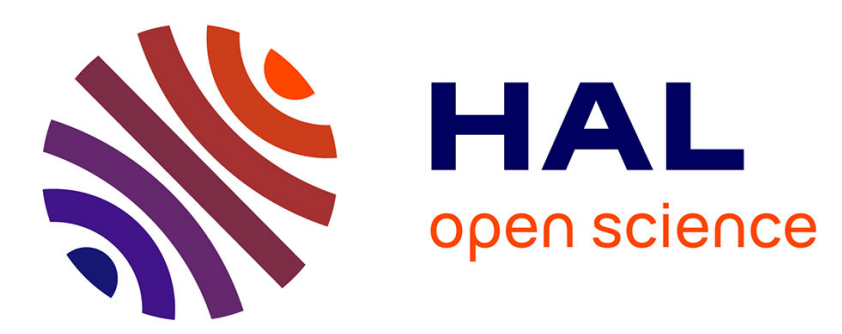

\title{
$\gamma \delta$ T cells amplify Blomia tropicalis -induced allergic airway disease
}

Augustin Belkadi, Céline Dietrich, François Machavoine, Jefferson Victor, Maria Leite-De-Moraes

\section{To cite this version:}

Augustin Belkadi, Céline Dietrich, François Machavoine, Jefferson Victor, Maria Leite-De-Moraes. $\gamma \delta$ T cells amplify Blomia tropicalis -induced allergic airway disease. Allergy, 2019, 74 (2), pp.395-398. 10.1111/all.13618. hal-02324259

\section{HAL Id: hal-02324259 \\ https://hal.science/hal-02324259}

Submitted on 5 Nov 2020

HAL is a multi-disciplinary open access archive for the deposit and dissemination of scientific research documents, whether they are published or not. The documents may come from teaching and research institutions in France or abroad, or from public or private research centers.
L'archive ouverte pluridisciplinaire HAL, est destinée au dépôt et à la diffusion de documents scientifiques de niveau recherche, publiés ou non, émanant des établissements d'enseignement et de recherche français ou étrangers, des laboratoires publics ou privés. 
$\gamma \delta \mathrm{T}$ cells amplify Blomia tropicalis-induced allergic airway disease

\section{Journal of Allergy and Clinical Immunology}

Section designation: Letter to the Editor
(1)

(1)

\author{
Augustin Belkadi, MS ${ }^{\mathrm{a}, *}$, Céline Dietrich, MS ${ }^{\mathrm{a}, *}$, François Machavoine, $\mathrm{MSc}^{\mathrm{a}}$, \\ Jefferson Russo Victor, $\mathrm{PhD}^{\mathrm{b}, \mathrm{c}, \mathrm{d}}$ and Maria Leite-de-Moraes, $\mathrm{PhD}^{\mathrm{a}}$
}

${ }^{a}$ Laboratory of Immunoregulation and Immunopathology, Institut Necker-Enfants Malades,

CNRS UMR 8253, INSERM UMR 1151 and Université Paris Descartes Sorbonne Paris Cité, 75015, Paris, France

${ }^{b}$ Laboratory of Medical Investigation LIM 56, Division of Clinical Dermatology, Medical School, University of Sao Paulo, Sao Paulo, Brazil

cDivision of Pathology, Medical School, University of Sao Paulo, Sao Paulo, Brazil

${ }^{\mathrm{d}}$ Division of Environmental Health, FMU, Laureate International Universities, Sao Paulo, Brazil.

*Both authors contributed equally to this work

\section{Corresponding author:}

Maria Leite-de-Moraes, Laboratory of Immunoregulation and Immunopathology, Institut Necker-Enfants Malades, CNRS UMR 8253, INSERM UMR 1151 and Université Paris Descartes Sorbonne Paris Cité, 75015, Paris, France.

E-mail: maria.leite-de-moraes@parisdecartes.fr

\section{Disclosure of potential conflict of interest:}

The authors declare that they have no relevant conflicts of interest.

\section{Acknowledgements:}

We are grateful to Momtchilo Russo and Michel Dy for discussions concerning B. tropicalis and allergic mechanisms and Bernhard Ryffel for giving us the first TCR $\delta^{-/}$mice to start our colony. We are indebted to the technical assistance of E. Panafieu and Rachel Rignaud and to 
33 the help of Clélia Comte with the histology figures. Our thanks go also to the Cytology and

34 Histology platforms of the INEM. This work was supported by grants from CNRS (Centre 35 National de la Recherche Scientifique), INSERM (Institut National de la Santé et de la 36 Recherche Médicale), Université Paris Descartes and Legs Poix (Chancellerie des universités 37 de Paris).

Authorship Contributions:

40 M.L.M conceived and designed the experiments.

41 A.B., C.D., F.M., and J.R.V. performed the research.

42 A.B., C.D., J.R.V., and M.L.M. analysed the data.

43 M.L.M. wrote the manuscript

\section{Text Count}

46 Word count in the body of manuscript: 997

47 Figures: 2 (+ 5 supplementary)

Tables: 1 supplementary

Key messages (2-3 independent bulleted statements)

- IL-4-producing $\mathrm{V} \gamma 1^{+} \gamma \delta \mathrm{T}$ cells promote allergic airway inflammation in a Blomia tropicalis model of asthma

- Human peripheral blood $\gamma \delta \mathrm{T}$ cells are activated in atopic B. tropicalis subjects compared to non-atopic donors.

\section{Key Words}

Blomia tropicalis; $\gamma \delta$ T cells, atopy; asthma; airway hyperreactivity; lung, IL-4, patients

Short title: $\gamma \delta$ T cells and Blomia tropicalis allergic immune responses

60

\section{ABBREVIATIONS}

AHR: airway hyperreactivity

64 BALF: bronchoalveolar lavage fluid

65 WT: wild type 
To the Editor:

Allergic asthma is a chronic and heterogeneous immunological disease characterized by airway inflammation, hyper-IgE production, mucus hypersecretion and airway hyperreactivity (AHR). The most studied house dust mites (HDM) respiratory allergens belong to Dermatophagoides pteronyssuns and Dermatophagoides farinae mite species. However, the storage mite Blomia tropicalis represents an important allergenic source and sensitization to its allergens are commonly associated with typical clinical manifestations of allergy, including asthma (1-3). Although these mites may coexist in tropical and subtropical regions, B. tropicalis is the major allergen in some countries $(4,5)$. A limited number of reports have focused on the allergic processes involved in the immune responses triggered by B. tropicalis $(3,6,7)$. Here, we used allergic asthma murine models and ex vivo analysis of $B$. tropicalis allergic subjects to better explore the role of immune cells in allergic responses obtained in the context of $B$. tropicalis exposure.

Mice received B. tropicalis allergens exclusively administered intranasally (without adjuvant) for both sensitization and challenge phases (Appendix S1). This model reproduced the major allergic asthma hallmarks, namely enhanced BALF cell counts accompanied by airway eosinophilia and airway hyperresponsiveness (AHR) (Figure 1A and B). We addressed the involvement of IL-4, as a major Th2 cytokine by comparing lung inflammation in IL-4-deficient (IL-4 ${ }^{-/}$) and wild-type (WT) mice. The lack of IL-4 resulted in the absence of the typical airway eosinophilia and AHR observed in WT mice following B. tropicalis sensitization and challenge (Figure S1A and B). These results show that IL-4 is required for B. tropicalis allergen-induced asthma in our model.

Distinct immune cells, such as iNKT cells and $\gamma \delta$ T cells, may be capable to secrete IL-4 and favour asthmatic inflammatory Th2-cytokine-dependent responses $(8,9)$. As previously described, iNKT cells can be divided into three major subsets, iNKT1 (IFN- $\gamma$ and 
IL-4 producers), iNKT2 (IL-4 producers) and iNKT17 (IL-17 producers) (10). These subsets were present in the lung of B. tropicalis treated mice (Figure S2A). No major differences were observed concerning their ability to secrete IL-4, IL-13 or IFN $\gamma$ but the frequency of IL17-producing iNKT cells was enhanced when compared to controls (Figure S2A). However, this enhanced frequency was not critical for airway inflammation since iNKT cell-deficient mice presented similar airway eosinophilia than WT mice (Figure S2B). Concerning $\gamma \delta \mathrm{T}$ cells, including the $\mathrm{V} \gamma 1.1^{+}$(hereafter mentioned as $\mathrm{V} \gamma 1^{+}$) $\gamma \delta \mathrm{T}$ cell subset, we found that their number were higher in the lung of $B$.tropicalis-treated than in NaCl-treated mice (Figure S3). It is noteworthy that airway eosinophilia and AHR were significantly reduced in B. tropicalis-sensitized and -challenged TCR $\delta^{-/-}$mice when compared to WT controls (Figure 1C, 1D). Further, IgE levels in the serum, Mucin-5 mRNA expression and mucus deposition in the lung were also impaired in $\mathrm{TCR} \delta^{-/-}$compared to WT mice (Figure S4). Previous reports have shown that the influence of $\gamma \delta$ T cells on allergic responses may be complex (9). Here, we focused our analysis on $\mathrm{V} \gamma 1^{+}$and $\mathrm{V} \gamma 1^{-} \gamma \delta \mathrm{T}$ cell subsets (Figure S5A). Among $\gamma \delta \mathrm{T}$ cells, IL-4 and IL-13 were mainly produced by the $\mathrm{V} \gamma 1^{+} \gamma \delta \mathrm{T}$ cell subset in the lungs of the asthmatic mice (Figure S5B and C). Of note, the frequency of IL-4 ${ }^{+}$ and IL- $13^{+}$among gated $\mathrm{V} \gamma 1^{+} \gamma \delta \mathrm{T}$ cells from B. tropicalis-treated mice was higher than in controls (Figure S5B). These cells also secreted higher levels of IFN $\gamma$ and IL-17 in asthmatic mice (Figure S5B). In contrast, the percentage of $\mathrm{IL}-4^{+}, \mathrm{IL}-13^{+}, \mathrm{IL}-17^{+}$and IFN $\gamma^{+}$among gated $\mathrm{V} \gamma 1^{-}$subset was similar in mice treated with B. tropicalis and controls (Figure S5B and C). These findings indicating that cytokine-producing $\mathrm{V} \gamma 1^{+} \gamma \delta \mathrm{T}$ cells may be critical for this inflammatory allergic response.

The enhanced frequency of IL-4-producing $V \gamma 1^{+} \gamma \delta$ T cells in the lung of B. tropicalistreated mice (Figure S5B) led us to the question whether airway eosinophilia and AHR could 
116 be restored by transferring fully competent $\mathrm{V} \gamma 1^{+} \gamma \delta \mathrm{T}$ cells to B. tropicalis-sensitized and -

117 challenged TCR $\delta^{-\sigma_{-}}$mice. This was the case since the adoptive transfer of $25000 \mathrm{~V} \gamma 1^{+} \gamma \delta \mathrm{T}$

118 cells from WT mice one hour before the first challenge restored airway inflammation,

119 particularly for airway eosinophilia, and $\mathrm{AHR}$ in $\mathrm{TCR} \delta^{-/}$mice (Figure 1E and F). In contrast,

120 adoptive transfer of $\mathrm{V} \gamma 1^{+} \gamma \delta \mathrm{T}$ cells from $\mathrm{IL}-4^{-/-}$mice had no effect (Figure $1 \mathrm{E}$ and $\mathrm{F}$ ). The

121 failure to develop an effective AHR response in $\mathrm{TCR} \delta^{-{ }^{-}}$mice and the inability of $\mathrm{V} \gamma 1^{+} \gamma \delta \mathrm{T}$

122 cells from $\mathrm{IL}-4^{-/-}$mice to restore AHR can be ascribed to the lack of IL-4 production by $\mathrm{V} \gamma 1^{+}$

$123 \gamma \delta$ T cells, which compromises their contribution to asthmatic symptoms. Thus, IL-4-

124 producing $\mathrm{V} \gamma 1^{+} \gamma \delta \mathrm{T}$ cells are required for airway inflammation and AHR in our B. tropicalis

125 asthma model.

126 We further addressed the relevance of $\gamma \delta \mathrm{T}$ cells to atopic immune process observed in

127 B. tropicalis allergic subjects. We obtained blood samples from subjects clinically classified

128 as atopic or non-atopic (no allergic responses to any tested allergen) to $B$. tropicalis allergens

129 (Table S1). The frequency of peripheral blood $\gamma \delta \mathrm{T}$ cells was significantly lower in $B$.

130 tropicalis atopic than non-atopic individuals (Figure 2A and S6). However, these cells were

131 more activated in atopic subjects, as they spontaneously produced higher levels of IFN $\gamma$ and

132 IL-4 than those of non-atopic donors (Figure 2B, 2C and S6). The frequency of IL-17-

133 producing $\gamma \delta \mathrm{T}$ cells was similar in atopic and non-atopic subjects (Figure 2D and S6).

134 Overall, these observations suggest that $\gamma \delta$ T cells may be involved in immune allergic

135 processes in B. tropicalis atopic patients. Further studies are required to determine the major

136 blood $\gamma \delta \mathrm{T}$ cell subsets activated in these patients.

137 This study has limitations since the precise nature of the stimuli (B. tropicalis antigens

138 or cytokines) required to induce IL-4 production by $\gamma \delta$ T cells and the analysis of these

139 lymphocytes in BALF from subjects susceptible to B. tropicalis remain to be determined. 
140 However, our findings provided many insights into how $\gamma \delta$ T cells may contribute to immune

141 allergic responses trigged by $B$. tropicalis. First, $\gamma \delta$-deficient mice provided unequivocal

142 evidence that the absence of $\gamma \delta$ T cells profoundly impairs the allergic asthma symptoms

143 induced by $B$. tropicalis sensitization and challenge under defined experimental conditions.

144 Moreover, airway eosinophilia and AHR in response to B. tropicalis where achieved only

145 when $\mathrm{V} \gamma 1^{+} \gamma \delta \mathrm{T}$ cells from WT, but not from $\mathrm{IL}_{-} 4^{--}$, mice were adoptively transferred to $\gamma \delta$ -

146 deficient mice. Consistent with this result, $\gamma \delta$ T cells were activated in B. tropicalis atopic

147 patients, as they produced higher levels of IFN $\gamma$ and IL-4 than non-atopic donors. In

148 conclusion, our results suggest an unanticipated role for $\gamma \delta$ T cells in allergic immune

149 responses induced by $B$. tropicalis.

150

157 From

158 a'Laboratory of Immunoregulation and Immunopathology, Institut Necker-Enfants Malades,

159 CNRS UMR 8253, INSERM UMR 1151 and Université Paris Descartes Sorbonne Paris Cité, 16075015 , Paris, France,

$161{ }^{\mathrm{b}}$ Laboratory of Medical Investigation LIM 56, Division of Clinical Dermatology, Medical

162 School, University of Sao Paulo, Sao Paulo, Brazil,

163 'Division of Pathology, Medical School, University of Sao Paulo, Sao Paulo, Brazil,

164 Division of Environmental Health, FMU, Laureate International Universities, Sao Paulo, 165 Brazil.

166

167 E-mail: maria.leite-de-moraes@parisdescartes.fr.

$168 *$ Both authors contributed equally to this work 


\section{Uncategorized References}

1. Guilleminault L, Viala-Gastan C. [Blomia tropicalis: A house dust mite in the tropics]. Rev Mal Respir. 2017;34:791-801.

2. Fernandez-Caldas E, Lockey RF. Blomia tropicalis, a mite whose time has come. Allergy. 2004;59:1161-1164.

3. Chua YL, Liong KH, Huang CH, Wong HS, Zhou Q, Ler SS, et al. Blomia tropicalisSpecific TCR Transgenic Th2 Cells Induce Inducible BALT and Severe Asthma in Mice by an IL-4/IL-13-Dependent Mechanism. J Immunol. 2016;197:3771-3781.

4. Puerta L, Fernandez-Caldas E, Mercado D, Lockey RF, Caraballo LR. Sequential determinations of Blomia tropicalis allergens in mattress and floor dust samples in a tropical city. J Allergy Clin Immunol. 1996;97:689-691.

5. Arlian LG, Morgan MS, Neal JS. Dust mite allergens: ecology and distribution. Curr Allergy Asthma Rep. 2002;2:401-411.

6. Barboza R, Camara NO, Gomes E, Sa-Nunes A, Florsheim E, Mirotti L, et al. Endotoxin Exposure during Sensitization to Blomia tropicalis Allergens Shifts TH2 Immunity Towards a TH17-Mediated Airway Neutrophilic Inflammation: Role of TLR4 and TLR2. PLoS One. 2013;8:e67115.

7. Baqueiro T, Russo M, Silva VM, Meirelles T, Oliveira PR, Gomes E, et al. Respiratory allergy to Blomia tropicalis: immune response in four syngeneic mouse strains and assessment of a low allergen-dose, short-term experimental model. Respir Res. 2010;11:51.

8. Lisbonne M, Diem S, de Castro Keller A, Lefort J, Araujo LM, Hachem P, et al. Cutting edge: invariant $\mathrm{V}$ alpha 14 NKT cells are required for allergen-induced airway inflammation and hyperreactivity in an experimental asthma model. J Immunol. 2003; 171:1637-1641.

9. Hahn YS, Taube C, Jin N, Sharp L, Wands JM, Aydintug MK, et al. Different potentials of gamma delta $\mathrm{T}$ cell subsets in regulating airway responsiveness: $\mathrm{V}$ gamma 1+ cells, but not $\mathrm{V}$ gamma 4+ cells, promote airway hyperreactivity, Th2 cytokines, and airway inflammation. J Immunol. 2004;172:2894-2902.

10. Michel ML, Keller AC, Paget C, Fujio M, Trottein F, Savage PB, et al. Identification of an IL-17-producing NK1.1(neg) iNKT cell population involved in airway neutrophilia. $J$ Exp Med. 2007;204:995-1001.

\section{LEGENDS}

Figure 1: $\gamma \delta$ T cells were required for asthma symptoms induced by B. tropicalis. (A, C, E) The number of total cells (Total), monocyte (Mono), eosinophil (Eosino), neutrophil (Neutro) and lymphocyte (Lympho) were determined in BALF of wild-type (WT) or TCR $\delta^{-/}$asthmatic (B. tropicalis) or non-asthmatic $(\mathrm{NaCl})$ mice $(\mathrm{n}=7$ to 20$)$. (B, D, F) Lung resistance (Rtr) was measured $24 \mathrm{~h}$ after the last $B$. tropicalis challenge or controls $(\mathrm{NaCl})(\mathrm{n}=7$ to 15$)$. (E, F) BALF cell counts (E) and lung resistance (Rtr) were measured $24 \mathrm{~h}$ after the last B. tropicalis challenge of WT, $\mathrm{TCR} \delta^{--}, \mathrm{TCR} \delta^{--}$mice adoptively transferred with sorted $\mathrm{V} \gamma 1^{+} \gamma \delta$ T cells from WT or $\mathrm{IL}^{-4^{-/}}$mice $(\mathrm{n}=5$ to 10$) . * \mathrm{p}<0.05 ; * * \mathrm{p}<0.01 ; * * * * \mathrm{p}<0.0001$.

Figure 2. $\gamma \delta$ T cells were activated in B. tropicalis atopic patients. (A) Percentages of $\gamma \delta$ T cells in PBMC from non-atopic versus B. tropicalis atopic subjects. (B, C, D) Frequency of spontaneous IFN $\gamma^{+}(\mathrm{B}), \mathrm{IL}_{-} 4^{+}(\mathrm{C})$ and $\mathrm{IL}-17 \mathrm{~A}^{+}(\mathrm{D})$ cells among gated $\gamma \delta \mathrm{T}$ cells from non-atopic versus $B$. tropicalis atopic subjects. 
217 
Table S1: Characteristics of the adults included in the study

\begin{tabular}{|c|c|c|c|}
\hline & Non-atopic & Bt-Atopic & $p$ \\
\hline Number & 15 & 13 & \\
\hline Age, years (mean $\pm \mathrm{SE})$ & $30.8 \pm 2.1$ & $29.6 \pm 2.8$ & 0.41 \\
\hline Sex (male/female) & $7 / 8$ & $7 / 6$ & 0.83 \\
\hline \multicolumn{4}{|l|}{ SPT results $(\mathrm{n} / \%)$} \\
\hline Blomia tropicalis & $0 / 0$ & $13 / 100$ & \\
\hline Dermatophagoides pteronyssinus & $0 / 0$ & $9 / 69$ & \\
\hline Dermatophagoides farinae & $0 / 0$ & $8 / 61$ & \\
\hline Aspergillus fumigatus & $0 / 0$ & $5 / 38$ & \\
\hline Canis familiaris & $0 / 0$ & $5 / 38$ & \\
\hline Alternaria alternata & $0 / 0$ & $4 / 30$ & \\
\hline Penicillium notatum & $0 / 0$ & $4 / 30$ & \\
\hline Felis domesticus & $0 / 0$ & $2 / 15$ & \\
\hline Cladosporium herbarum & $0 / 0$ & $1 / 8$ & \\
\hline Periplaneta americana & $0 / 0$ & $0 / 0$ & \\
\hline \multicolumn{4}{|l|}{ Others } \\
\hline Clinical manifestation (past 6 mo) & $0 / 0$ & $13 / 100$ & \\
\hline Regular use of antihistamines & $0 / 0$ & $13 / 100$ & \\
\hline
\end{tabular}

SPT - Skin prick test; mo - months 
$\gamma \delta \mathrm{T}$ cells amplify Blomia tropicalis-induced allergic airway disease

Augustin Belkadi, MS ${ }^{\mathrm{a}, *}$, Céline Dietrich, MS a,*, François Machavoine, MSc ${ }^{\mathrm{a}}$, Jefferson Russo Victor, $\mathrm{PhD}^{\mathrm{b}, \mathrm{c}, \mathrm{d}}$ and Maria Leite-de-Moraes, $\mathrm{PhD}^{\mathrm{a}}$

\section{On-line repository}

\section{METHODS}

\section{Mice and reagents}

Eight to ten-week-old specific pathogen-free C57BL/6J, IL-4 $4^{-/}$and $\mathrm{TCR} \delta^{-/-}$mice were bred in our facility. All animal experiments were carried out according to the guidelines for care and use of animals approved by the French Institutional Committee (APAFIS\#4105201511171831592).

\section{Airway allergen sensitization and challenge model.}

To induce allergic airway inflammation, we adapted a previously described protocol (1). In brief, mice were sensitized and challenged by intranasal administrations of B. tropicalis extracts (Greer laboratories, USA) at day 0 (D0) with $100 \mu \mathrm{g} /$ mouse then at D7, D9, D11, D14 and D16 with $50 \mu \mathrm{g} / \mathrm{mouse}$.

Twenty-four hours after the last challenge, mice were anesthetized with a mixture of ketamine $(150 \mathrm{mg} / \mathrm{kg})$ and xylasine $(400 \mu \mathrm{g} / \mathrm{kg})$ and their tracheas were cannulated (tracheostomy with ligation). FlexiVent apparatus (SCIREQ) was used to access airwayspecific resistance (Rn, tidal volume of $10 \mathrm{ml} / \mathrm{kg}$ at a respiratory rate of $150 \mathrm{breath} / \mathrm{min}$ in response to increasing doses of aerosolized acetyl- $\beta$-methylcholine chloride (methacholine; Sigma-Aldrich). Assessments were performed at least three times and the maximum $\mathrm{R}$ value obtained after each dose of methacholine was used for the measure.

Airway inflammation was assessed in cytospin preparations of cells in bronchoalveolar lavage fluid (BALF, $3 \times 0.5 \mathrm{~mL}$ washes with PBS) that were stained with May-Grünwald/Giemsa (Merck). For some experiments, BALF cells were also analysed by flow cytometry.

\section{Adoptive transfer}

In some experiments, $25 \times 10^{3}$ electronically sorted $\mathrm{V} \gamma 1^{+}$or $\mathrm{V} \gamma 1^{-} \gamma \delta \mathrm{T}$ cells were adoptively transferred intravenously (i.v.) to B. tropicalis immunized mice $1 \mathrm{~h}$ before the first challenge

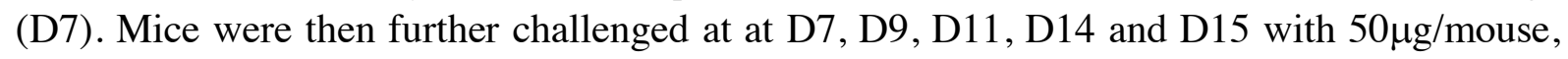
as described above.

\section{Leucocytes from lung tissues}

Lung tissues were cut into pieces using a GentleMACS Dissociator (Miltenyi Biotec) and treated with collagenase type 4 (Thermo Fischer Scientific) plus DNAse I (Roche). The lymphocyte-enriched fraction was collected at the 35-70\% interface of Percoll gradients (GE Healthcare). Cells were immediately stained or stimulated for $4 \mathrm{~h}$ with $10^{-8} \mathrm{M}$ PMA and $1 \mu \mathrm{g}$ $\mathrm{ml}^{-1}$ ionomycin, in the presence of $10 \mu \mathrm{g} \mathrm{ml}^{-1}$ brefeldin A (all from Sigma-Aldrich).

\section{Immunofluorescence.}

Murine cells were incubated with CD1d-PBS57-APC tetramers, anti-TCR $\beta$-APCeFluor780, anti-V $\gamma 1.1-\mathrm{PE}$ and anti-TCR $\gamma \delta$-BV605 (Biolegend). Fixable viability dye was used to exclude dead cells (ThermoFischer Scientific). For intracellular staining, cells were further fixed with $4 \%$ PFA, washed, and permeabilized with $0.5 \%$ saponin (Sigma-Aldrich), and then incubated 
with anti-IL-17-PerCPCy5.5, anti-IL-4-PE-Cy7, anti-IFN- $\gamma$-V450, anti-anti-IL-13-PE-eF610 or isotype control (eBiosciences). The cells were washed and fluorescence was detected using a LSRFortessa (Becton Dickinson) and further analysed using the FlowJo 10.4.1 software (Tree Star).

\section{$\gamma \delta \mathrm{T}$ cell sorting.}

Splenocytes from WT or IL-4 ${ }^{-/}$mice, isolated as previously described $(2,3)$, were labelled with anti-V $\gamma 1-\mathrm{PE}$ and anti-TCR $\gamma \delta-\mathrm{BV} 605$, as described above, and then sorted using a FACSAria cell sorter (Becton Dickinson).

\section{mRNA expression.}

RNAs were extracted using the RNeasy Plus Minikit (Qiagen) including a DNase treatment. Then RNA was reverse transcribed using the High Capacity RNA-to-cDNA Kit (ThermoFisher Scientific), according to the manufacturer's instructions. Primers and probes for real-time PCR were provided by ThermoFisher Scientific under references: Mucin 5b (Muc5b): Mm00466391_m1 and HPRT: Mm01545399_m1. All reactions were performed in triplicate with TaqMan ${ }^{\circledR}$ Fast Advanced Master Mix according to the supplier's instructions for a Step One Plus apparatus (ThermoFisher Scientific). All data were normalized to the internal standard, namely HPRT expression in each sample, and expressed as relative expression using the $\Delta \Delta \mathrm{Ct}$ method versus the reference sample.

\section{Histology of the airways.}

Lungs were fixed with $10 \%$ formalin via the trachea, removed and stored in $10 \%$ formalin. Lung tissues were embedded into paraffin and $3 \mu \mathrm{m}$ sections were stained with periodic acid Schiff (PAS).

\section{Patient samples}

Blood samples were collected from subjects who were previously clinically classified as atopic or non-atopic individuals and voluntarily subjected to a skin prick test (SPT) to confirm the atopic state. These individuals were classified into two groups: as Bt- atopic individuals (clinically allergic and reactive to Blomia tropicalis extract, with co-reaction to at least one allergen), and non-atopic individuals (without any clinical allergy symptoms and not reactive to any tested allergen). Additional information about these individuals is shown in table 1 .

Each sample of peripheral blood mononuclear cells (PBMCs) was provided from a different donor. The ethics committees at the HCor and the School of Medicine at the University of São Paulo approved this study (CAAE: 15507613.4.0000.0060).

\section{Skin prick test (SPT) and blood sample collection}

The SPT were performed in accordance with European standards (4) with an adapted panel of allergens that included the profile of Brazilian allergens (i.e., Blomia tropicalis, Canis familiaris, Periplaneta americana, Aspergillus fumigatus, Penicillium notatum, Alternaria alternata, Cladosporium herbarum, Dermatophagoides pteronyssinus, Dermatophagoides farinae, and Felis domesticus - IPI ASAC), as previously described (5).

Briefly, one drop of each allergen extract or controls was applied to the volar forearm and a superficial skin puncture was made using a hypodermic needle (Alko, Brazil). After 15 minutes, the results were considered positive when wheals measure reach a diameter of $3 \mathrm{~mm}$ greater than that of the negative control. We excluded patients who used antihistamines, glucocorticosteroids or certain other systemic drugs that can influence the SPT results within 15 days before the test or with severe eczema or dermographism. 


\section{Human flow cytometry}

Flow cytometry using human PBMCs to evaluate phenotype and spontaneous intracellular cytokine production were performed as previously described (6, 7). Briefly, PBMC separations were performed using Ficoll-Paque Plus (GE Healthcare) after centrifugation and suspensions of PBMCs were phenotypic evaluated ex vivo or cultured to intracellular cytokine production evaluation. PBMCs were stained with mouse anti-human $\gamma \delta$ TCR-FITC, CD161PECy5 or isotype control antibodies (BD Pharmingen).

To evaluate intracellular cytokine production, PBMCs were cultured in RPMI 1640 medium containing 10\% FBS and $1 \mu \mathrm{g} / \mathrm{mL}$ of Brefeldin A (Sigma-Aldrich) for 24 hours without additional stimulus. Cultured PBMCs were then washed, fixed with formaldehyde and stained with mouse anti-human $\gamma \delta$ TCR-FITC, IL-17A-Alexa700, IL-4-PECy7, IFN- $\gamma$ HorizonV450 or isotype control antibodies (BD Pharmingen) in $100 \mu \mathrm{L}$ of PBS containing $0.05 \%$ saponin. Thirty minutes later, PBMCs were washed, fixed, acquired using a LSRFortessa cytometer (BD Biosciences, USA), and analysis was performed using FlowJo software 10.1 (Tree Star).

\section{Statistics}

Data are expressed as means \pm SEM. The AHR values were analysed with repeated- measures 2-way ANOVA followed by Bonferroni correction as a post-hoc test. All other values were analysed with Mann-Whitney $\mathrm{U}$ test. Results were considered significant at a $P$ value of 0.05 or less $\left(* p<0.05 ;{ }^{* *} p<0.01 ;{ }^{* * *} p<0.001\right)$. Data were analyzed using GraphPad Prism version 6 (GraphPad Software).

\section{LEGENDS}

Figure S1: IL-4-producing cells were required for asthma symptoms induced by B. tropicalis. (A) The number of total cells (Total), monocyte (Mono), eosinophil (Eosino), neutrophil (Neutro) and lymphocyte (Lympho) were determined in BALF of wild-type (WT) or IL-4 ${ }^{-/}$ asthmatic (B. tropicalis) mice. (B) Lung resistance (Rtr) was measured 24h after the last $B$. tropicalis challenge or controls $(\mathrm{NaCl})(\mathrm{n}=7$ to 15$)$.

Figure S2: iNKT cells were not required for asthma symptoms induced by B. tropicalis. (A) A representative Facs profile showing the gating strategy used to identify iNKT (CD1d tetramer ${ }^{+}$TCR $\beta^{+}$) cells and the percentage of IFN $\gamma$, IL-4, IL-13 and IL-17A positive cells, and their respective isotype controls, among gated iNKT cells in the lungs of WT asthmatic ( $B$. tropicalis) or non-asthmatic $(\mathrm{NaCl})$ mice.

(B) The number of total cells (Total), monocyte (Mono), eosinophil (Eosino), neutrophil (Neutro) and lymphocyte (Lympho) were determined in BALF of wild-type (WT) or iNKT $\left(\mathrm{J} \alpha 18^{-/}\right)$-deficient asthmatic (B. tropicalis) mice. ( $\mathrm{n}=5$ to 7 ).

Figure S3: $\gamma \delta \mathrm{T}$ cells and the $V \gamma 1^{+} \gamma \delta \mathrm{T}$ cell subset were enhanced in the lung of B. tropicalis asthmatic mice. (A) A representative Facs profile showing the gating strategy used to identify $\mathrm{TCR} \gamma \delta^{+}$and $\mathrm{V} \gamma 1^{+} \gamma \delta \mathrm{T}$ cells. (B) The number of total $\gamma \delta \mathrm{T}$ cells and of the $\mathrm{V} \gamma 1^{+} \gamma \delta \mathrm{T}$ cell subset were determined in the lungs of wild-type asthmatic (B. tropicalis) or non-asthmatic $(\mathrm{NaCl})$ mice $(\mathrm{n}=5$ to 10$)$.

Figure S4: Impaired seric IgE and mucus production in the lung of $\mathrm{TCR} \delta^{-/}$B. tropicalis asthmatic mice. (A) Total IgE levels in the serum of $\mathrm{WT}$ and $\mathrm{TCR} \delta^{-/-}$mice following $B$. tropicalis or $\mathrm{NaCl}$ administration (B) Mucin-5 mRNA expression assessed by quantitative RT-PCR in the lung of WT and TCR $\delta^{-/}$mice following B. tropicalis or $\mathrm{NaCl}$ administration. 
Data are representative of two experiments. (C) Representative PAS-stained lung histology sections of controls $(\mathrm{NaCl})$ and $B$. tropicalis-sensitized and -challenged WT and TCR $\delta^{-/-}$mice. Following $B$. tropicalis administration, the airways of WT mice contained more PAS-stained mucus-producing cells than $\mathrm{TCR} \delta^{-/-}$mice.

Figure S5. Distinct cytokine production by lung $\mathrm{V} \gamma 1^{+}$and $V \gamma 1^{-} \gamma \delta \mathrm{T}$ cell subsets. (A) Flow cytometric gating strategy used to identify $\mathrm{TCR} \delta^{+} \mathrm{V} \gamma 1^{+}$and $\mathrm{TCR} \delta^{+} \mathrm{V} \gamma 1^{-} \gamma \delta \mathrm{T}$ cell subsets and the frequency of these cells in the lung of B. tropicalis- versus NaCl-treated mice. (B, C) A representative Facs profile showing the percentage of IFN $\gamma$, IL-4, IL-13 and IL-17A positive cells among gated $\mathrm{TCR} \delta^{+} \mathrm{V} \gamma 1^{+}(\mathrm{B})$ and $\mathrm{TCR} \delta^{+} \mathrm{V} \gamma 1^{-}(\mathrm{C}) \gamma \delta \mathrm{T}$ cell subsets and their frequency in the lungs of WT asthmatic (B. tropicalis) or non-asthmatic $(\mathrm{NaCl})$ mice. ${ }^{*} \mathrm{p}<0.05$. (D) Facs profile represents the respective IL-13 versus IL-4 and IL-17A versus IFN- $\gamma$ isotype controls.

Figure S6. $\gamma \delta \mathrm{T}$ cells were activated in B. tropicalis atopic patients. (A) Gate strategy to obtain viable lymphocytes. (B) A representative Facs profile showing the gating strategy used to identify TCR $\gamma \delta^{+}$cells and the percentage of IFN $\gamma$, IL-4, IL-13 and IL-17A positive cells among gated TCR $\gamma \delta^{+}$cells.

\section{REFERENCES}

1. Zhou Q, Ho AW, Schlitzer A, Tang Y, Wong KH, Wong FH, et al. GM-CSF-licensed CD11b+ lung dendritic cells orchestrate Th2 immunity to Blomia tropicalis. J Immunol. 2014;193:496-509.

2. Massot B, Michel ML, Diem S, Ohnmacht C, Latour S, Dy M, et al. TLR-induced cytokines promote effective proinflammatory natural Th17 cell responses. J Immunol. 2014;192:5635-5642.

3. Michel ML, Lenoir C, Massot B, Diem S, Pasquier B, Sawa S, et al. SLAM-associated protein favors the development of iNKT2 over iNKT17 cells. Eur J Immunol. 2016;46:2162-2174.

4. Heinzerling L, Mari A, Bergmann KC, Bresciani M, Burbach G, Darsow U, et al. The skin prick testEuropean standards. Clin Transl Allergy. 2013;3:3.

5. Sgnotto FDR, Oliveira MG, Lira AAL, Bento-de-Souza L, Duarte AJDS, Victor JR. Low doses of IgG from atopic individuals can modulate in vitro IFN- $\gamma$ production by human intra-thymic TCD4 and TCD8 cells: an IVIg comparative approach. Hum Vaccin Immunother. 2017:0.

6. de Oliveira MG, Oliveira LM, Lira AAL, Sgnotto FDR, Duarte AJDS, Sato MN, et al. Preconception allergen sensitization can induce B10 cells in offspring: a potential main role for maternal IgG. Allergy Asthma Clin Immunol. 2017;13:22.

7. Sgnotto FDR, de Oliveira MG, Lira AAL, Inoue AHS, Titz TO, Orfali RL, et al. IgG from atopic dermatitis patients induces IL-17 and IL-10 production in infant intrathymic TCD4 and TCD8 cells. Int $J$ Dermatol. 2018;57:434-440. 
A

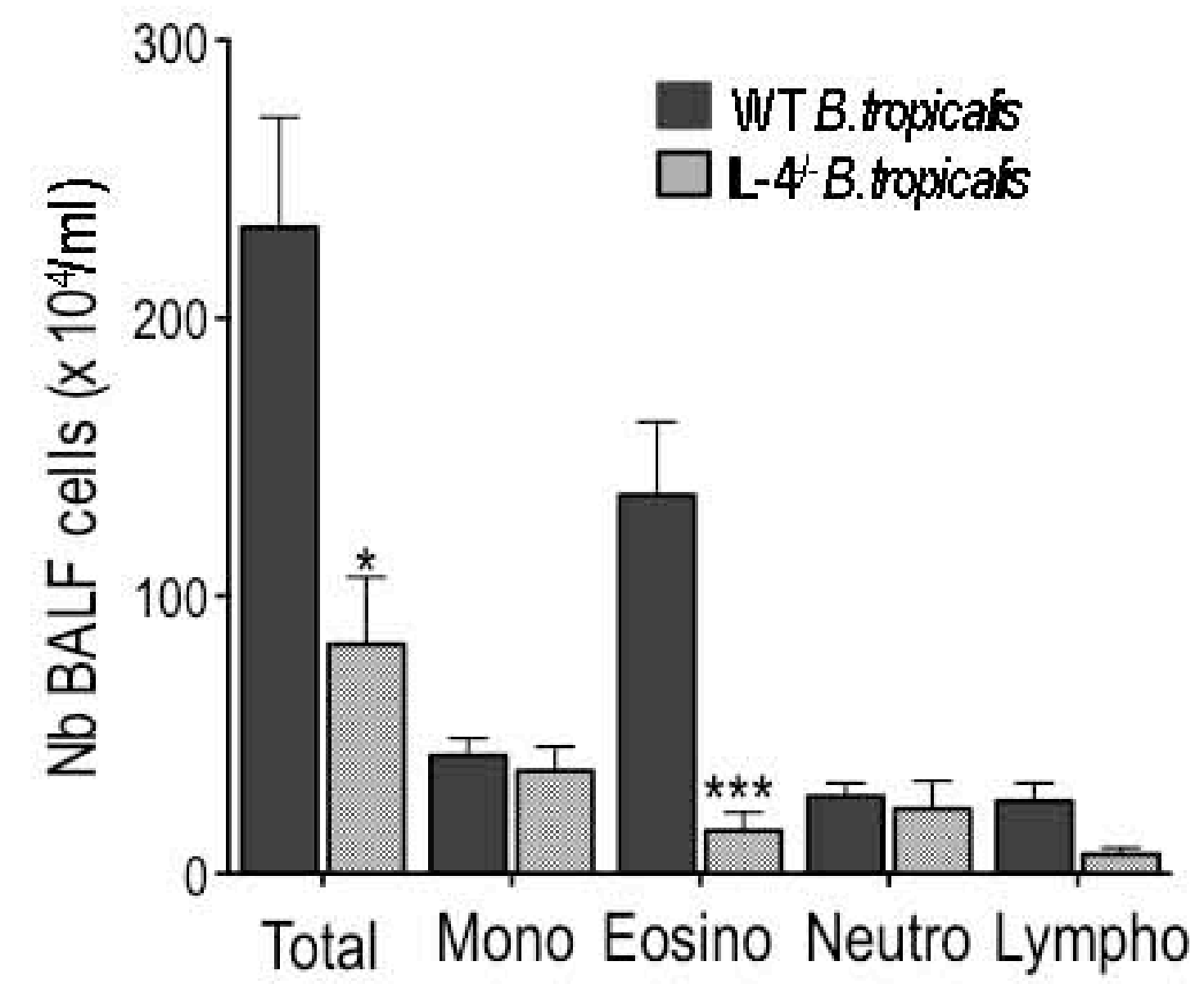

B

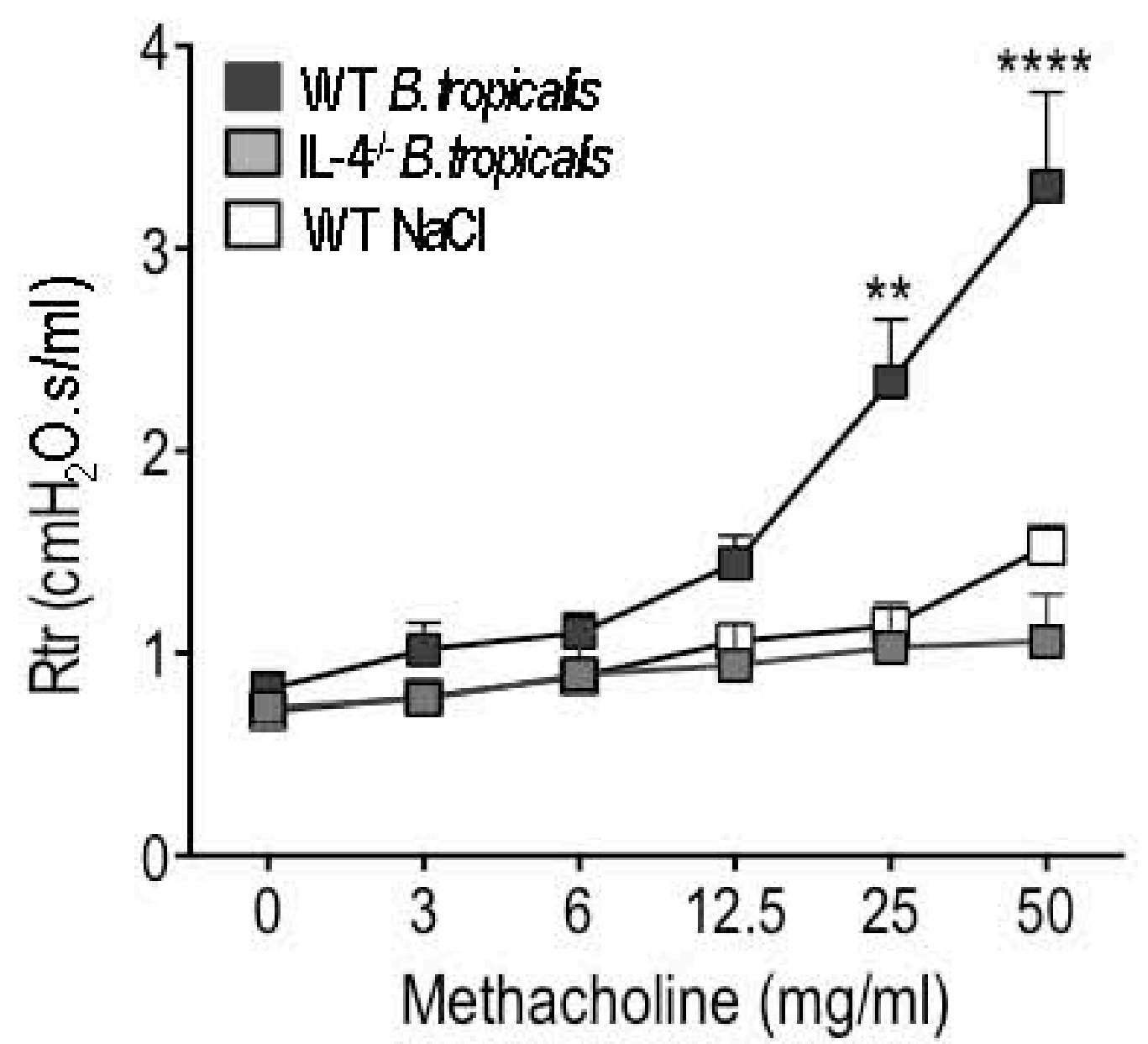

Figure S1 

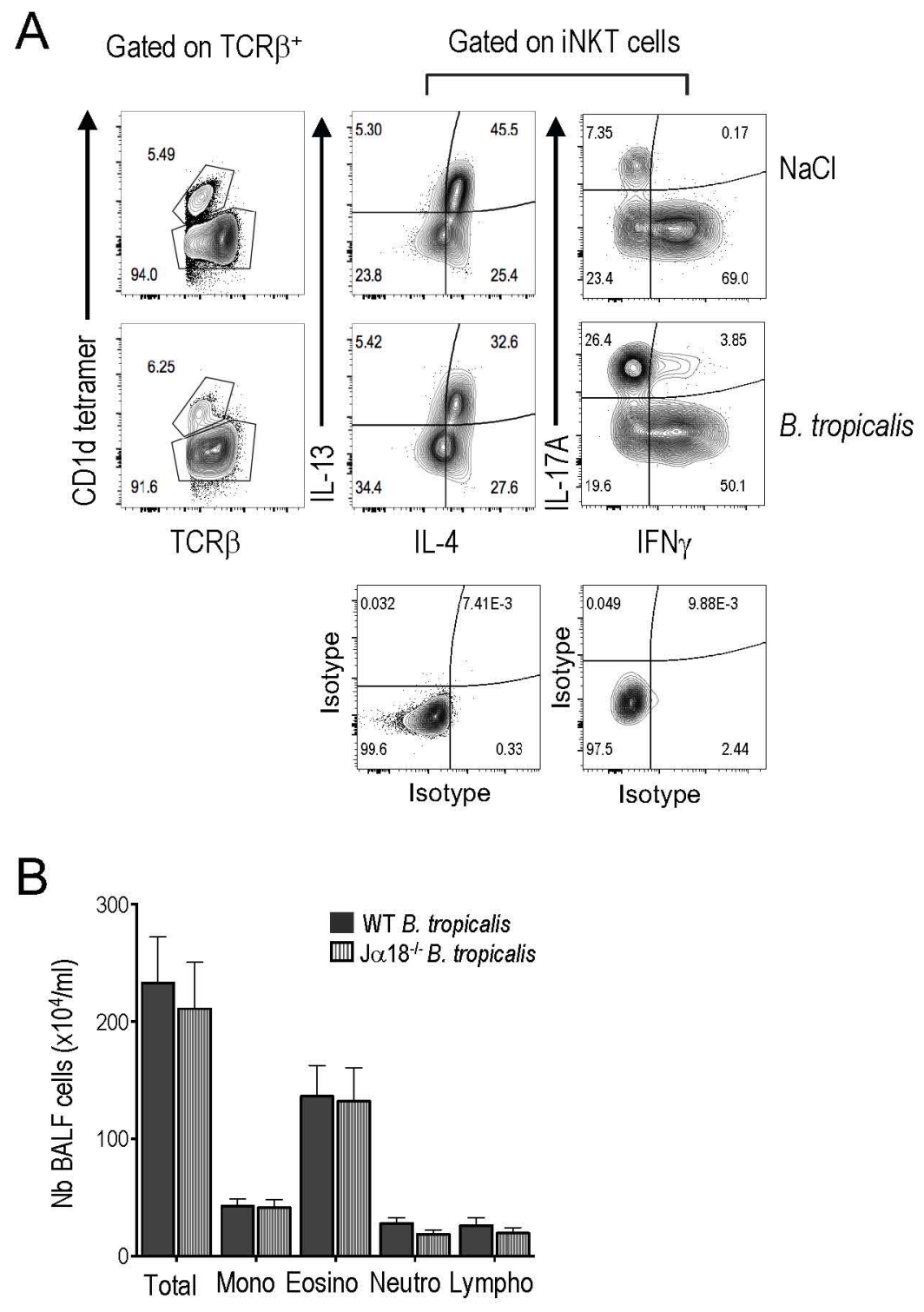

Figure S2 
A
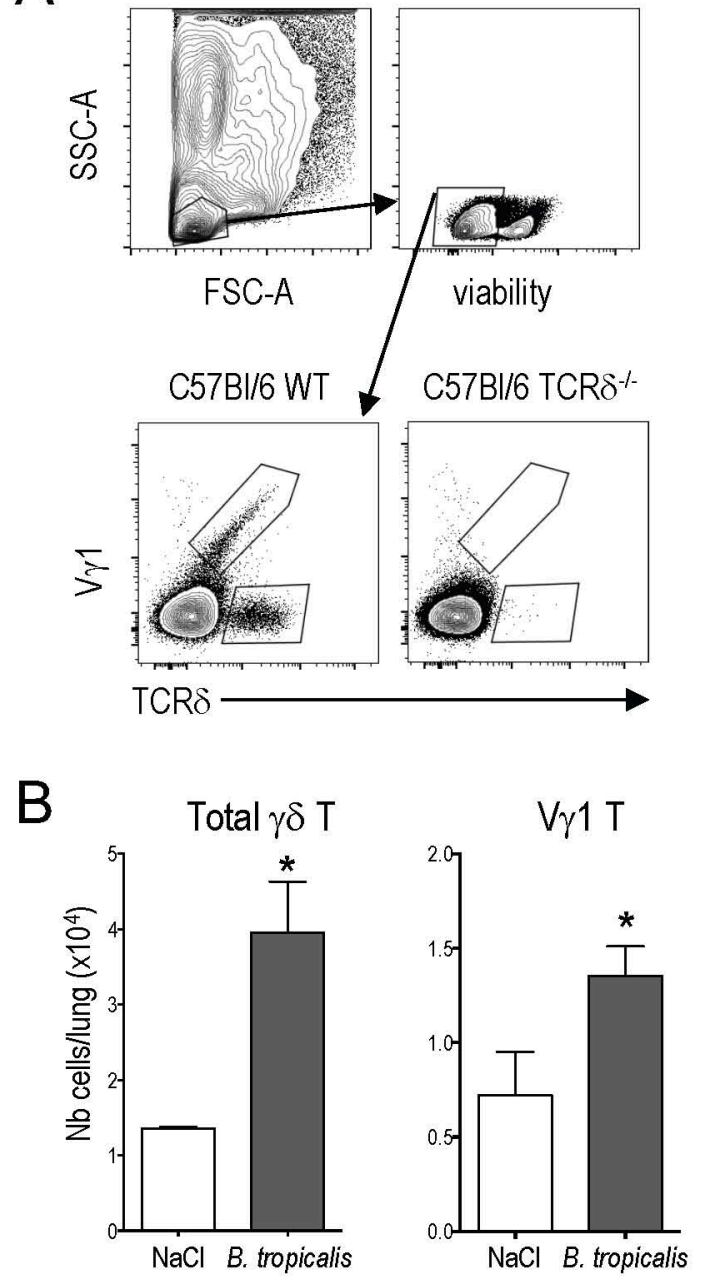

Figure S3 


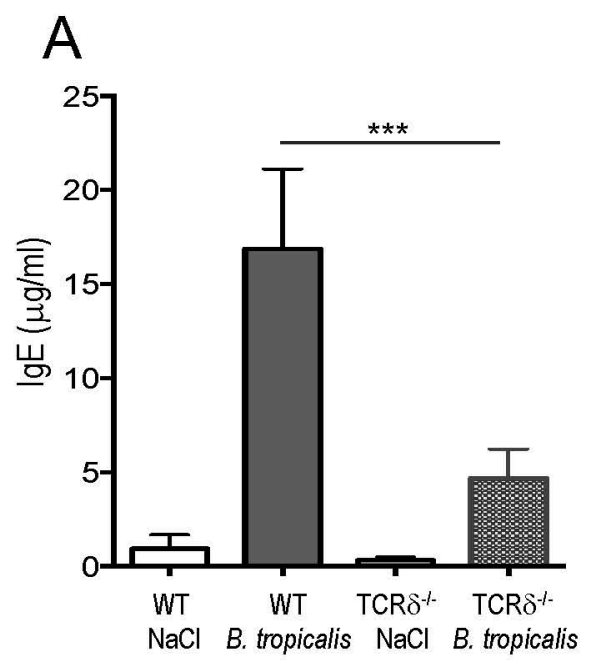

B

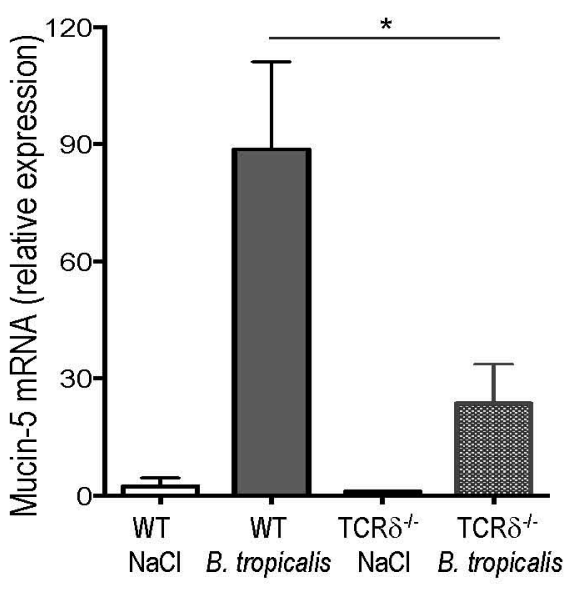

C

Wild-type

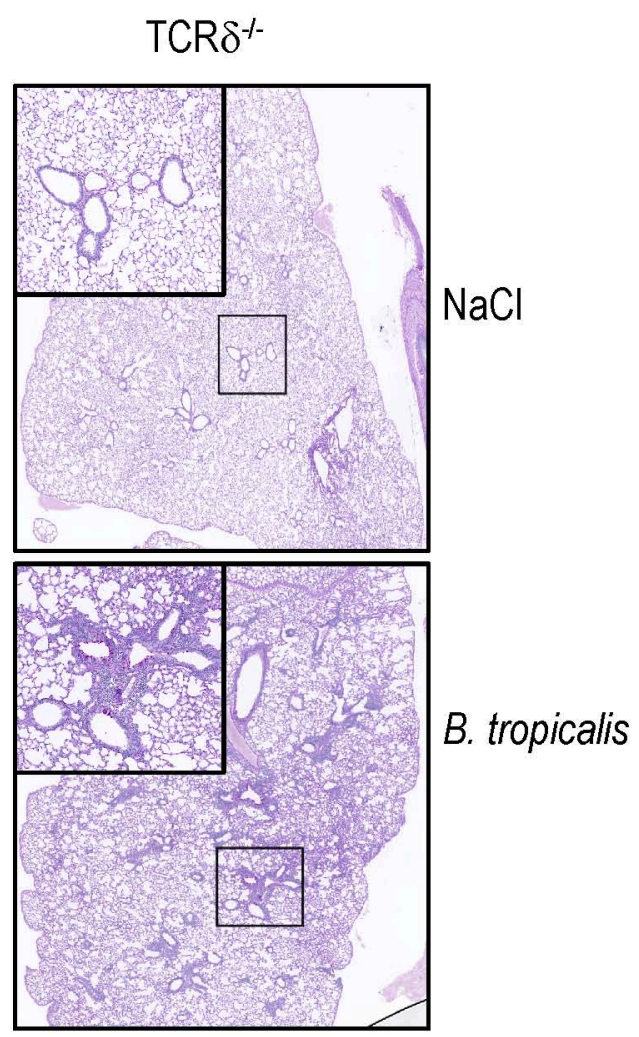

Figure S4 
A
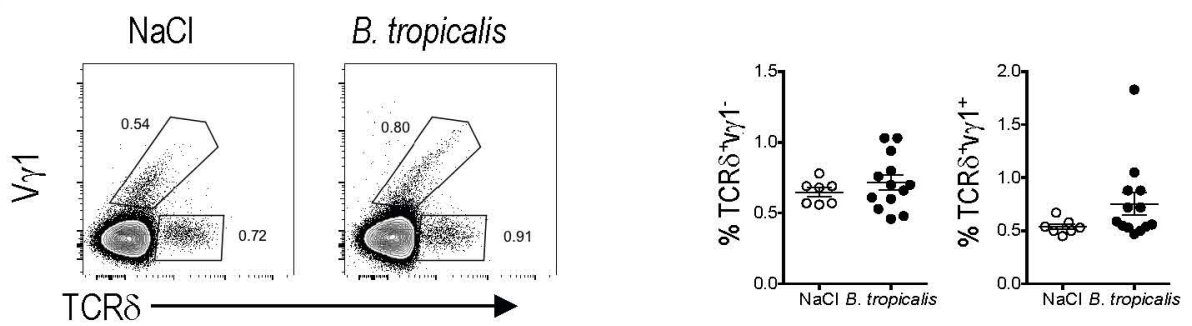

B Gated on $T C R \delta^{+} V_{\gamma} 1^{+} T$ cells

Gated on TCR $\delta^{+} V_{\gamma}{ }^{+}+T$ cells
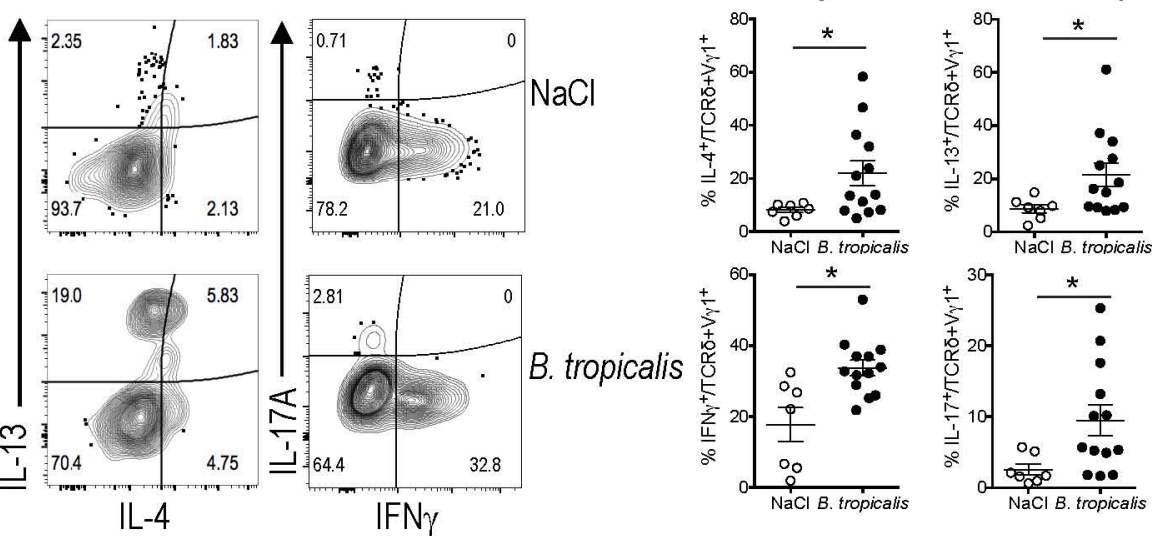

C

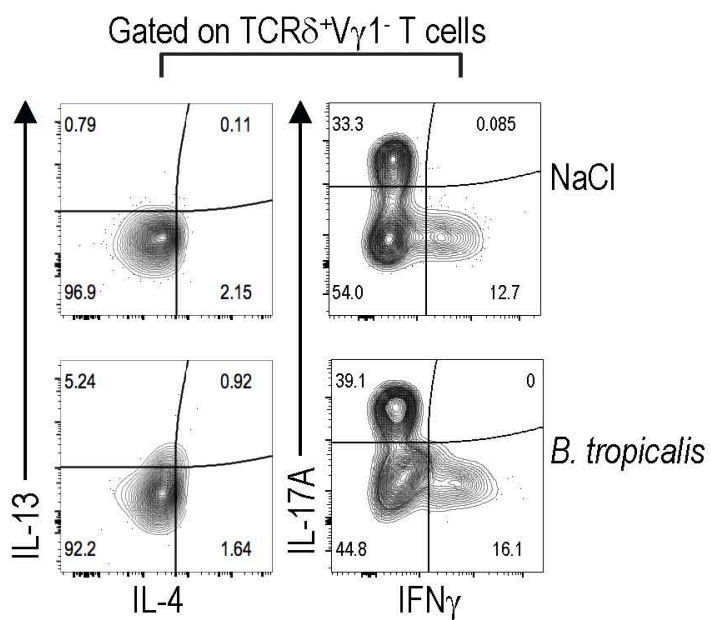

Gated on TCR $\delta^{+} \mathrm{V} \gamma 1^{-} \mathrm{T}$ cells
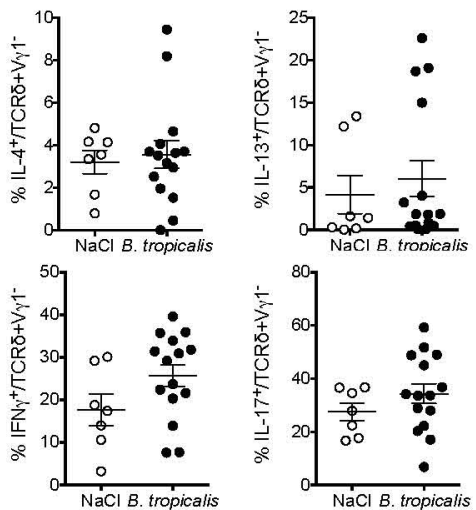

D

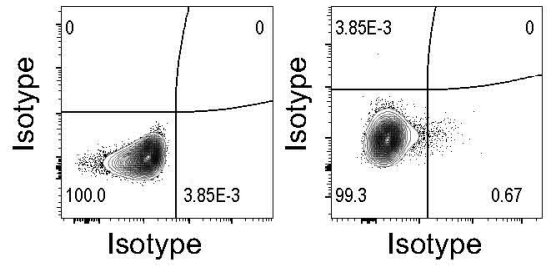

Figure S5 

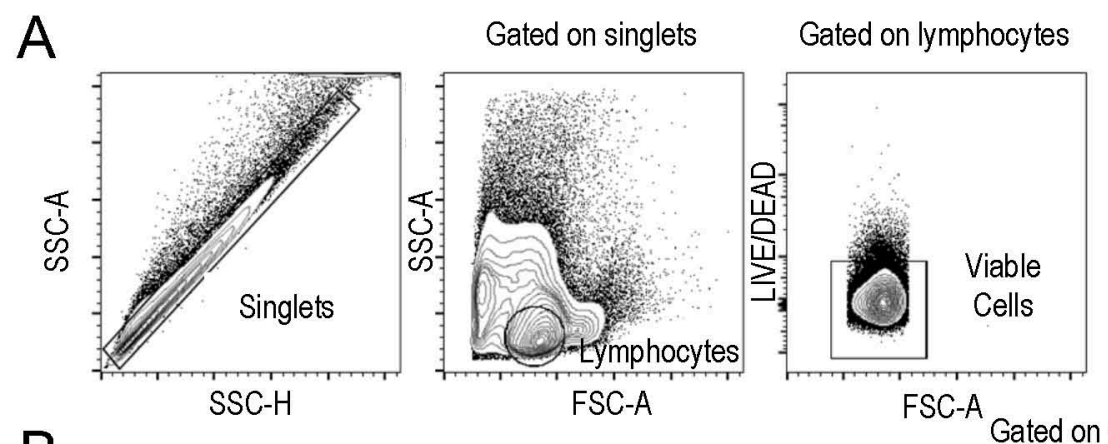

B Gated on viable lymphocytes

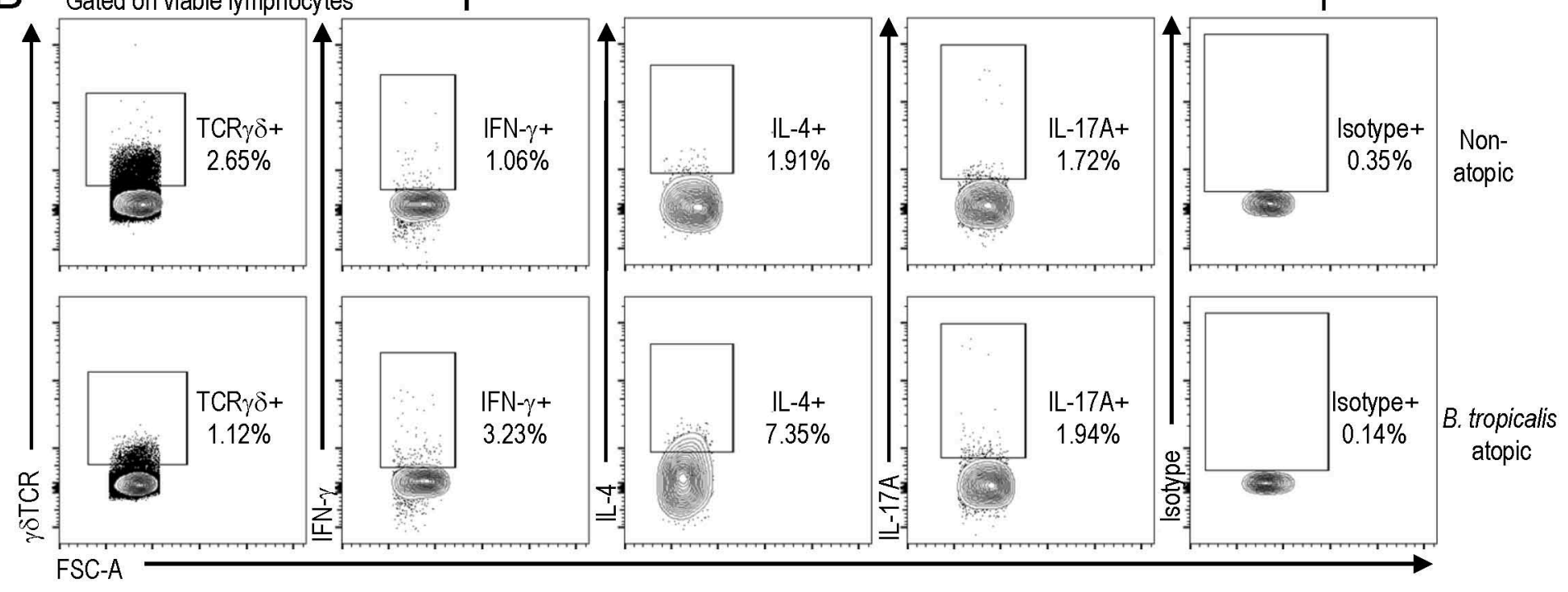

Figure S6 